Vol. 1 No. 2 September 2021 e-ISSN : 2797-3344 P-ISSN : 2797-3336

\title{
PENINGKATAN PRESTASI BELAJAR BAHASA INDONESIA MELALUI PENERAPAN MODEL PEMBELAJARAN PICTURE AND PICTURE PADA SISWA KELAS II SDN 2 DASAN LEKONG KECAMATAN SUKAMULIA TAHUN PELAJARAN 2020/2021
}

\author{
SITI FATIMAH \\ SDN 2 Dasan Lekong Kabupaten Lombok Timur \\ Siti.fatimah@gmail.com
}

\begin{abstract}
ABSTRAK
Penelitian Tindakan Kelas (PTK) ini dilakukan dengan tujuan adalah untuk mengetahui peningkatan Prestasi belajar bahasa Indonesia materi puisi melalui penerapan model pembelajaran picture and picture pada siswa Kelas II di SDN 2 Dasan Lekong Tahun pelajaran 2020/2021. Penelitian Tindakan Kelas ( PTK ) ini dilakukan dalam tahapan 2 siklus, dan dari hasil tindakan yang sudah dilakukan terbukti dapat meningkatkan hasil/prestasi belajar siswa baik dari segi ketuntasan belajar siswa secara klasikal yaitu pada siklus I sebesar $65 \%$, dapat meningkat menjadi $90 \%$ pada siklus II maupun dari segi nilai rata-rata hasil evaluasi yakni pada siklus I sebesar Berapa menjadi Berapa pada siklus II, ini berarti ada peningkatan sebesar $25 \%$. Dari hasil penelitian tindakan kelas ini juga menunjukkan adanya peningkatan tingkat aktivitas belajar siswa dari 3,2 kategori Cukup Aktif pada siklus I menjadi 4,1 kategori Aktif, berarti ada peningkatan.
\end{abstract}

Kata Kunci: Prestasi Belajar, Model Pembelajaran Picture and Picture

\section{ABSTRACT}

This Classroom Action Research (CAR) was conducted with the aim of knowing the improvement of Indonesian language learning achievement in poetry material through the application of the picture and picture learning model to Class II students at SDN 2 Dasan Lekong for the 2020/2021 academic year. This Classroom Action Research (CAR) was carried out in stages 2 cycles, and from the results of the actions that have been carried out it is proven to be able to improve student learning outcomes/achievements both in terms of classical student learning completeness, namely in the first cycle of $65 \%$, it can increase to $90 \%$ in the first cycle. cycle II as well as in terms of the average value of the evaluation results, namely in the first cycle of How much to How much in the second cycle, this means that there is an increase of $25 \%$. From the results of this classroom action research, it also showed an increase in the level of student learning activity from 3.2 quite active categories in the first cycle to 4.1 active categories, meaning there was an increase.

Keywords: Learning Achievement, Picture and Picture Learning Model

\section{PENDAHULUAN}

Manusia sejak lahir kedunia sudah mendapatkan pendidikan hingga ia masuk di bangku sekolah. kata pendidikan sudah tidak asing lagi sehingga semua manusia pasti membutuhkan pendidikan, ini berarti betapa pentingnya suatu pendidikan yang dapat memberikan kontribusi kepada manusia dalam menjalankan kehidupan dalam lingungan sosial masyarakat.

Menurut Ki Hajar Dewantara menyatakan bahwa pendidikan adalah suatu tuntunan didalam hidup tumbuhnya anak-anak. maksudnya ialah bahwa pendidikan menuntun segala kekuatan kodrat yang ada pada peserta didik agar sebagai manusia dan anggota masyarakat dapat mencapai keselamatan dan kebahagiaan hidup yang setinggi-tingginya. Menurut Ahmad D. Marimb mengemukakan bahwa pendidikan adalah suatu proses bimbingan yang dilaksanakan secara sadar oleh pendidik terhadap suatu proses perkembangan jasmani dan rohani peserta didik, yang tujunannya agar kepribadian peserta diidik terbentuk dengan sangat ungggul. kepribadian yang dimaksud ini bermakna cukup dalam yaitu pribadi yang tidak hanya pintar, pandai secara akademis saja, akan tetapi baik juga secara karakter. 
Menurut Carter V. Good mengartikan bahwa pendidikan sebagai suatu proses perkembangan kecakapan seseorang dalam bentuk sikap dan perilaku yang berlaku dalam masyarakat. proses dimana seseorang dipengaruhi oleh lingkungan yang terpimpim khususnya dalam lingkungan sekolah sehingga dapat mencapai kecakapan sosial.

Untuk mengetahui definisi pendidikan dalam perspektif kebijakan,kita telah memiliki rumusan formal dan operasional sebagaimana termaktub dalam UU No.20 Tahun 2003.tentang SISDIKNAS,bahwa pendidikan adalah usaha dasar dan terncana untuk mewujudkan suasana belajar adan proses pemebelajaran agar peserta didik secara aktif mengembangkan potensi didrinya untuk memiliki kekuatan spiritual keagamaan,penegndalian diri,kepribadian,kecerdasan,ahlak mulia,serta keterampilan yang diperlukan dirinya,masyarakat,bangsa dan Negara. Berdasarkan definisi diatas saya menemukan 3 (tiga) pokok pikiran utama yang terkandung didalamnya, yaitu (1) usaha sadar dan terencana, (2) mewujudkan suasana belajar dan proses pembelajaran agar peserta didik aktif mengembangkan potensi dirinya, dan (3) memiliki kekuatan spiritual keagamaan, pengendalian diri, kepribadian, kecerdasan, ahlak mulia, serta keterampilan yang diperlukan dirinya, masyaratkat, bangsa dan Negara.

Sekolah dasar (disingkat SD) adalah jenjang paling dasar pada pendidikan formal di Indonesia.sekolah dasar ditempuh dalam waktu 6 tahun, mulai dari kelas 1 sampai dengan kelas 6. lulusan sekolah dasar dapat melanjutkan pendidikan ke sekolah pertama (atau sederajat). dalam UU sistem pendidikan nasional (UU No.20 Tahun 2001) pasal 17. mendefinisikan pendidikan dasar sebagai berikut:

1. Pendidikan dasar merupakan jenjang pendidikan yang melandasi jenjang pendidikan menengah.

2. Pendididkan dasar berbentuk sekolah dasar (SD) dan madrasah ibtidaiyah (MI) atau bentuk lain yang sederajat serta sekolah menengah pertama (SMP) dan Madrasah tsanawiyah (MTS) atau bentuk laun yang sederajat.

Hakikat bahasa Indonesia manusia adalah makhluk social yang pempunyai naluri untuk senantiasa hidup bersama.manusia harus mengadakan interaksi social untuk dapat hidup dengan sesama,karena interaksi social merupakan kunci semua khidupan social,tanpa interaksi social tidak mungkin ada kehidupan bersama.syarat terjadinya interaksi social yaitu adanya kontrak social dan komunikasi kontrak social merupakan tahap pertama terjadi interaksi social.seorang individu atau kelompok yang menyadari keberadaan individu atau kelompok yang lain dan menghendaki terciptanya interaksi sosila harus mengadakan komunikasi.oleh sebab itu,manusia harus memiliki alat komunikasi yang disebut bahasa.jadi hakikat bahasa dapat dimaksudkan bahasa menjadi alat komunikasi yang diperlukan dalam komuniksi antar manusia sebagai makhluk social.

Bahasa adalah suatu system dari lambang bunyi artbitre (mana suka) yang dipergunakan oleh anggota masyarakat untuk bekerja sama, berinteraksi, atau mengidentifikasi diri (krida laksana,1993). menurut (keraf,1984: 17) bahasa adalah alat komunikasi antar anggota masyarakat yang berupa lambang bunyi, suara, yang dihasilkan oleh alat ucap manusia. sifat-sifat bahasa antara lain:

1. Bahasa bersifat sistematik yaitu bahasa memiliki pola dan kaidah yang harus ditaati agar dapat dipahami oleh pemakainya. bahasa diatur oleh sistem. setiap bahasa mengandung dua sistem yaitu sistem bunyi dan sistem makna.

2. Bahasa bersifat mana suka yakni bahasa dipilih dari unsur-unsurnya secara acak tanpa dasar. tidak ada hubungan logis antara makna dan bunyi disimbolkan bahasa terbentuk atas kesepakatan-kesepakatan.

3. Bahasa bersifat ujar yakni hakikat bahasa yang sebenarnya adalah bunyi yang dihasilkan oleh articulator (alat ucap) sehinggga bahasa yang sebenarnya adalah bahasa lisan ynag diujarkan oleh manusia.

4. Bahasa bersifat manusiawi yakni bahasa menjadi berfungsi selama manusia yang menggunakan dan memanfaatkannya, bukan makhluk lain. 
5. Bahasa bersifat komunikatif yakni bahasa mempunyai arti penting dalam kehidupan sehari-hari yaitu sebagai alat komunikasi perhubungan antar sesama manusia sebagai alat interaksi.

Dalam melaksanakan proses pembelajaran pada mata pelajaran bahasa Indonesia di Kelas II SDN 2 Dasan Lekong ternyata penulis banyak menjumpai permaslahan antara lain:

1. Siswa kurang termotivasi untuk belajar

2. Hasil belajar mata pelajaran bahasa Indonesia sangat rendah

3. Guru dalam proses pembelajaran masih bersifat konvensional atau ceramah saja

4. Siswa sering tidak masuk sekolah

5. Siswa kurang aktif dalam pembelajaran

Karena keterbatasan waktu dan kemampuan penulis maka permasalahan yang penulis coba carikan penyelesaiannya yaitu hasil belajar bahasa Indonesia sanagat rendah dan salah satu langkah penyelesaian masalah tersebut yang penulis lakukan adalah penerapan penggunaan model pariabel bebas dan pembelajran dikelas.

Oleh karena itu, penulis melakukan penelitian tindakan kelas dengan judul "Peningkatan Prestasi Belajar Bahasa Indonesia Pada Materi Puisi melalui model pembelajaran picture and picture Di Kelas II SDN 2 Sukamulia Kec.Sukamulia Tahun Pelajaran 2020/2021".

\section{METODE PENELITIAN}

Subyek penelitian adalah siswa Kelas II SDN 2 Dasan Lekong kecamatan Sukamulia kabupaten Lombok Timur tahun pelajaran 2020/2021 yang berjumlah 17 siswa dan terdiri atas 14 siswa laki-laki dan 3 siswa prempuan dengan usia rata-rata 12-13 tahun.

Penelitian ini dilaksanakan di Kelas II SDN 2 Dasan Lekong Kecamatan Sukamulia kabupaten Lombok Timur yang merupakan tempat tugas peneliti. Penelitian ini dilaksanakan dengan menggunakan dua siklus, dengan setiap siklusnya dilaksanakan 2 kali pertemuan pada pembelajaran. Penelitian ini dilaksanakan selama kurang lebih tiga bulan, yaitu mulai Bulan Oktober sampai dengan Desember 2020.

Adapun prosedur penelitian pada tiap siklus terdiri dari perencanaan, pelaksanaan, observasi, dan refleksi. Instrument pengumpulan data terdiri dari dokumentasi, observasi dan tes. Sumber data penelitian ini berasal dari peneliti, guru sebagai observer, dan siswa Kelas II semester II SDN 2 Dasan Lekong.

\section{HASIL DAN PEMBAHASAN}

\section{Siklus I}

\section{Perencanaan}

Pada tahap ini yang akan dilakukan adalah kegiatan membuat rencana pelaksanaan pembelajaran, hasil evaluasi, lembar observasi, aktifitas siswa pada pertemuan I, kisi-kisi soal evaluasi, kunci jawaban dan pedoman penskoran.

\section{Pelaksanaan}

Dalam tahap pelaksanaan tindakan dilaksanakan kegiatan pembelajaran sesuai dengan rencana pelaksanaan pembelajaran yang telah dibuat. Untuk dapat menyesuaikan rencana pelaksanaan pembelajaran dalam penyampaian materi, termasuk didalamnya pembelajaran dengan menggunakan Model Pembelajaran Picture And Picture untuk materi Puisi dilaksanakan dalam 3 kali pertemuan, dimana 2 kali pertemuan untuk penyampaian materi yaitu pekan pertama dan 1 kali pertemuan untuk evaluasi yaitu pekan kedua bulan Nopember 2020 . Observasi

Hasil observasi diperoleh dari hasil pengamatan yang dilakukan oleh observer yang dilakukan oleh rekan guru peneliti dengan mengisi lembar observasi aktivitas guru dan aktivitas siswa untuk merekam jalannya proses pembelajaran. Dari hasil observasi dan pengamatan yang dilakukan, didapatkan bahwa proses pembelajaran belum sesuai dengan yang diharapkan karena masih terdapat kekurangan-kekurangan baik dari pihak guru sendiri maupun dari pihak 
siswa, antara lain; Guru belum memaksimalkan peran siswa dalam pembelajaran, masih ada siswa yang tidak aktif dalam kegiatan berdiskusi/mengerjakan tugas kelompok dari materi pelajaran yang dipelajari.

Berdasarkan hasil observasi terhadap aktivitas siswa setelah dianalisa diperoleh data sebagai berikut:

Tabel 1. Hasil Observasi Aktivitas Siswa Pada Siklus I

\begin{tabular}{|c|c|c|c|c|c|c|c|c|c|}
\hline \multirow{2}{*}{ Pertemuan } & \multicolumn{6}{|c|}{ Jumlah skor yang tampak } & \multirow{2}{*}{$\begin{array}{c}\Sigma \text { Skor } \\
\text { aktivitas }\end{array}$} & \multirow{2}{*}{$\begin{array}{l}\text { Rata-rata } \\
\text { Aktivitas }\end{array}$} & \multirow{2}{*}{ Kategori } \\
\hline & 1 & 2 & 3 & 4 & 5 & 6 & & & \\
\hline Pertama & 3 & 2,7 & 27 & 2,3 & 2,7 & 2,3 & 15,7 & 2,6 & $\begin{array}{l}\text { Cukup } \\
\text { Aktif }\end{array}$ \\
\hline Kedua & 3,3 & 3,7 & 3 & 3 & 3 & 3 & 19 & 3,2 & $\begin{array}{l}\text { Cukup } \\
\text { Aktif }\end{array}$ \\
\hline
\end{tabular}

Dari tabel di atas dapat dilihat bahwa aktivitas belajar siswa pada siklus I pertemuan 1 adalah 2,6 dengan kategori Cukup Aktif dan pertemuan 2 adalah 3,2 kategori Cukup Aktif. Tingkat aktivitas siswa ini tergolong Cukup Aktif. Oleh karena itu maka aktivitas siswa pada siklus berikutnya masih perlu ditingkatkan. Berdasarkan hasil evaluasi pada siklus 1 setelah dianalisis diperoleh data sebagai berikut:

Tabel 2. Hasil Evaluasi Belajar Siswa Pada Siklus I

\begin{tabular}{|c|c|c|c|c|c|}
\hline No. & Nama Siswa & $\mathrm{L} / \mathrm{P}$ & Skor & Nilai & $\begin{array}{c}\text { Tuntas/ Tidak } \\
\text { Tuntas(KKM=67) }\end{array}$ \\
\hline 1. & ABD.GANII & $\mathrm{L}$ & 18 & 90 & Tuntas \\
\hline 2. & ABIYU ISTISHAM PUTRA & $\mathrm{L}$ & 14 & 70 & Tuntas \\
\hline 3. & AL GIFARI & $\mathrm{L}$ & 16 & 80 & Tuntas \\
\hline 4. & ARKA PERAMANTA & $\mathrm{L}$ & 12 & 60 & Tidak Tuntas \\
\hline 5 . & DANANG RIZAL HAMDI & $\mathrm{L}$ & 13 & 65 & Tidak Tuntas \\
\hline 6. & $\begin{array}{l}\text { DENTA GDE AMARJITA } \\
\text { NUSABRA }\end{array}$ & $\mathrm{L}$ & 16 & 80 & Tuntas \\
\hline 7. & EDA PUTRIDA & $\mathrm{P}$ & 13 & 65 & Tidak Tuntas \\
\hline 8. & ELISA JULIANI & $\mathrm{P}$ & 13 & 65 & Tidak Tuntas \\
\hline 9. & FABIYAN RISQI ANANDA & $\mathrm{L}$ & 12 & 60 & Tidak Tuntas \\
\hline 10. & JILAN PRATAMA & $\mathrm{L}$ & 14 & 70 & Tuntas \\
\hline 11. & MAULIDA BAHAGIA PRAPTA & $P$ & 14 & 70 & Tuntas \\
\hline 12. & M . FAIRISKI IJTIHAT & $\mathrm{L}$ & 16 & 80 & Tuntas \\
\hline 13. & M.FAIS SAPARAS & $\mathrm{L}$ & 13 & 65 & Tidak Tuntas \\
\hline 14 & MUH. RIPKI & $\mathrm{L}$ & 18 & 90 & Tuntas \\
\hline 15 & M.SULTAN ASRUL & $\mathrm{L}$ & 14 & 70 & Tuntas \\
\hline 16. & NUYON & $\mathrm{L}$ & 18 & 90 & Tuntas \\
\hline \multirow[t]{5}{*}{17.} & LENO & $\mathrm{L}$ & 14 & 70 & Tuntas \\
\hline & Jumlah & & & 1470 & \\
\hline & Nilai Rata-rata & & & 73,5 & \\
\hline & Jumlah Siswa Yang Tuntas & & & 14 & \\
\hline & Persentase Ketuntasan Klasikal & & & $70 \%$ & \\
\hline
\end{tabular}

Dari tabel di atas dapat dilihat bahwa ketuntasan belajar yang dicapai siswa adalah 70 $\%$ dengan nilai rata-rata 73,5 . Hasil ini belum mencapai ketuntasan belajar secara klasikal sehingga pembelajaran dilanjutkan ke siklus berikutnya.

\section{Refleksi}

Berdasarkan analisis hasil observasi pada siklus I, jumlah siswa yang tuntas masih 70 $\%$ berarti masih dibawah standar minimum yakni $85 \%$. Hasil tersebut belum mencapai hasil yang diharapkan, untuk itu peneliti melanjutkan ke siklus berikutnya. Dalam siklus I ini terdapat kekurangan-kekurangan yang perlu untuk dipehatikan dan diperbaiki pada kegiatan siklus II diantaranya: (1) Pemberian motivasi dan apersepsi yang masih kurang membuat siswa sedikit kebingungan dalam menerima materi atau pokok bahasan baru dengan menerapkan pembelajaran kooperatif sehingga pada siklus II pemberian motivasi dan apersepsi lebih diperhatikan. (2) Meminta siswa untuk lebih aktif dalam berdiskusi, (tidak hanya diam memperhatikan teman-temannya bekerja dan hanya mengobrol dengan temannya. (3) Meminta 
siswa agar lebih aktif dan bertanya jika mendapat kesulitan atau jika ada materi dan soal-soal diskusi yang belum dimengerti. (4) Kesimpulan yang belum jelas membuat siswa sedikit bingung atau kurang jelas dengan batasan materi yang disampaikan guru sehingga pada siklus II pemberian kesimpulan lebih diperhatikan.

\section{Siklus II}

\section{Perencanaan}

Pada tahap ini yang akan dilakukan adalah kegiatan membuat rencana pelaksanaan pembelajaran, lembar observasi aktivitas guru pada siklus II pertemuan 1, lembar observasi aktivitas guru pada siklus II pertemuan 2, lembar observasi aktivitas siswa pada siklus II pertemuan 1, dan lembar observasi aktivitas siswa pada siklus II pertemuan 2, kisi-kisi soal evaluasi siklus II, instrumen evaluasi siklus II, kunci jawaban instrumen evaluasi dan pedoman penskoran, hasil evaluasi siklus II.

\section{Pelaksanaan}

Dalam tahap pelaksanaan tindakan dilaksanakan kegiatan pembelajaran sesuai dengan rencana pelaksanaan pembelajaran yang telah dibuat. Untuk dapat menyesuaikan rencana pelaksanaan pembelajaran dalam penyampaian materi, termasuk didalamnya pembelajaran dengan menggunakan Model Pembelajaran Picture And Picture untuk materi Puisi dilaksanakan dalam 3 kali pertemuan, dimana 2 kali pertemuan untuk penyampaian materi yaitu pekan ketiga dan 1 kali pertemuan untuk evaluasi yaitu pekan keempat bulan Nopember 2020 .

\section{Observasi}

Hasil observasi diperoleh dari hasil pengamatan yang dilakukan oleh observer yang dilakukan oleh rekan guru peneliti dengan mengisi lembar observasi aktivitas guru dan aktivitas siswa untuk merekam jalannya proses pembelajaran. Pada saat pembelajaran siklus II telah dilakukan perbaikan, dari analisis hasil observasi aktivitas siswa pada siklus II didapat bahwa aktivitas siswa tergolong aktif dalam setiap pertemuan. Hal ini dapat dilihat pada tabel skor aktivitas siswa mengalami peningkatan dari pertemuan pertama ke pertemuan ke dua, seperti yang terlihat pada tabel dibawah ini.

Tabel 3. Hasil Observasi Aktivitas Siswa Pada Siklus II

\begin{tabular}{|c|c|c|c|c|c|c|c|c|c|}
\hline \multirow{2}{*}{ Pertemuan } & \multicolumn{6}{|c|}{ Jumlah skor yang tampak } & \multirow{2}{*}{$\begin{array}{c}\sum \text { Skor } \\
\text { aktivitas }\end{array}$} & \multirow{2}{*}{$\begin{array}{l}\text { Rata-rata } \\
\text { Aktivitas }\end{array}$} & \multirow{2}{*}{ Kategori } \\
\hline & 1 & 2 & 3 & 4 & 5 & 6 & & & \\
\hline Pertama & 4, & 3 & 4,3 & 4 & 3 & 3 & 21,6 & 3,6 & Aktif \\
\hline Kedua & 4 & 4 & 4 & 4,3 & 4 & 43 & 24,6 & 4,1 & Aktif \\
\hline
\end{tabular}

Dari tabel di atas dilihat bahwa aktivitas siswa pada siklus II untuk pertemuan 1 adalah 3,6 dan pertemuan 2 adalah 4,1. Berdasarkan penggolongan aktivitas belajar siswa maka kategori aktivitas siswa pada siklus II adalah tergolong Aktif. Berdasarkan hasil evaluasi pada siklus II setelah dianalisis diperoleh data sebagai berikut:

Tabel 4. Hasil belajar yang diperoleh siswa pada siklus II

\begin{tabular}{clcccl}
\hline No. & \multicolumn{1}{c}{ Nama Siswa } & L/P & Skor & Nilai & $\begin{array}{c}\text { Tuntas/ } \\
\text { Tidak Tuntas }\end{array}$ \\
1. & ABD GANI & L & 18 & 90 & Tuntas \\
2. & ABIYU ISTISHAM PUTRA & $\mathrm{L}$ & 15 & 75 & Tuntas \\
3. & AL GIFARI & $\mathrm{L}$ & 18 & 90 & Tuntas \\
4. & ARKA PERAMANTA & $\mathrm{L}$ & 14 & 70 & Tuntas \\
5. & DANANG RISAL HAMDI & $\mathrm{L}$ & 14 & 70 & Tuntas \\
6. & DENTA GDE AMARJTA & $\mathrm{L}$ & 16 & 80 & Tuntas \\
7. & NUSABRA & & & & \\
8. & ELISA PUTRIDA & $\mathrm{P}$ & 14 & 70 & Tuntas \\
9. & FABIYAN RISQI ANANDA & $\mathrm{L}$ & 14 & 70 & Tuntas \\
10. & JILAN PRATAMA & $\mathrm{L}$ & 14 & 70 & Tuntas \\
11. & MAULIDA BAHAGIA PRAPTA & $\mathrm{P}$ & 18 & 90 & Tuntas \\
\hline
\end{tabular}


Vol. 1 No. 2 September 2021 e-ISSN : 2797-3344 P-ISSN : 2797-3336

$\begin{array}{lllrrr}\text { 12. } & \text { M. FAIRISKI IJTIHAD } & \text { L } & 18 & 90 & \text { Tuntas } \\ \text { 13. } & \text { M. PAIS SAPARAS } & \text { L } & 18 & 70 & \text { Tuntas } \\ \text { 14. } & \text { MUH. RIPKI } & \text { L } & 14 & 70 & \text { Tuntas } \\ \text { 15. } & \text { M. SULTAN ASRUL } & \text { L } & 16 & 80 & \text { Tuntas } \\ \text { 16. } & \text { NUYON } & \text { L } & 19 & 95 & \text { Tuntas } \\ \text { 17. } & \text { LENO } & \text { L } & 16 & 80 & \text { Tuntas } \\ & \text { Jumlah } & & & 1580 & \\ \text { Nilai Rata-rata } & & & 79 & \\ & \text { Jumlah Siswa Yang Tuntas } & & & 17 & \\ \text { Persentase Ketuntasan Klasikal } & & & 100 \% & \end{array}$

Hasil evaluasi yang diperoleh pada siklus II ini mencapai tingkat $100 \%$ jadi sudah dapat dikatakan tuntas, untuk itu tidak perlu lagi diadakan pembelajaran pada siklus berikutnya dengan ketuntasan belajar yang sudah dicapai, dengan demikian pembelajaran dengan menerapkan Model Pembelajaran Picture and Picture dikatakan dapat meningkatkan Prestasi belajar Bahasa Indonesia pada materi Puisi.

\section{Refleksi}

Dari hasil observasi aktivitas siswa pada siklus II, kegiatan pembelajaran sudah dapat berjalan dengan baik, dimana hasil observasi aktivitas siswa dapat tergolong Aktif dilihat dari setiap kegiatan pembelajaran begitu juga aktivitas guru sudah tergolong Baik Sekali. Dari hasil analisis terhadap hasil evaluasinya terjadi peningkatan rata-rata kelas maupun persentase ketuntasan secara klasikal sudah mencapai/melebihi $85 \%$ artinya sudah $85 \%$ atau lebih siswa sudah mencapai nilai hasil ulangan sebesar KKM atau melebihi KKM yang ditentukan. Oleh karena itu penelitian ini dihentikan sampai siklus II sesuai dengan perencanaan.

\section{Pembahasan}

Penelitian tindakan kelas ini dilaksanakan sebagai upaya untuk meningkatkan Prestasi belajar Bahasa Indonesia materi Puisi pada siswa Kelas II Semester II dengan melaksanakan pembelajaran dengan menerapkan/menggunakan Model Pembelajaran Picture and Picture di SDN 2 Dasan Lekong Tahun Pembelajaran 2020/2021.

Berdasarkan hasil analisis data pada tiap siklus, terlihat bahwa hasil dari siklus I ke siklus II mengalami peningkatan. Pada pelaksanaan pembelajaran dan hasil analisis data siklus I, untuk aktivitas siswa diperoleh nilai rata-rata sebesar 3,2 dan aktivitas siswa pada siklus II diperoleh nilai rata-rata kelas sebesar 3,6, Pada pelaksanaan pembelajaran dan hasil analisis data siklus I, untuk aktivitas guru diperoleh nilai rata-rata sebesar 2,8 dan aktivitas guru pada siklus II diperoleh nilai rata-rata sebesar 3,1.

Terkait dengan hasil ulangan pada siklus I dan II dapat dilihat rinciannya dibawah ini:

Tabel 5. Ringkasan Hasil Evaluasi Pada Siklus I

\begin{tabular}{llc}
\hline No & \multicolumn{1}{c}{ Uraian } & Hasil \\
1 & Nilai Terendah & 60 \\
2 & Nilai Tertinggi & 90 \\
3 & Rata-rata & 73,5 \\
4 & Jumlah siswa yang tuntas & 14 \\
5 & Jumlah siswa yang ikut tes & 20 \\
6 & Persentase yang tuntas & $70 \%$ \\
\hline
\end{tabular}

Sedangkan pada siklus II hasilnya sebagai berikut:

Tabel 6. Ringkasan Hasil Evaluasi Pada Siklus II

\begin{tabular}{llc} 
No & \multicolumn{1}{c}{ Uraian } & Hasil \\
1 & Skor Terendah & 70 \\
2 & Skor Tertinggi & 95 \\
3 & Rata-rata & 79 \\
4 & Jumlah siswa yang tuntas & 17 \\
5 & Jumlah siswa yang ikut tes & 17 \\
\hline
\end{tabular}


Setelah melihat kedua tabel hasil evaluasi dari siklus I dan II dimana nilai yang mereka peroleh sudah mencapai tingkat ketuntasan belajar. Dan melebihi tingkat ketuntasan belajar secara klasikal yaitu $85 \%$. Untuk lebih rincinya peningkatan tingkat ketuntasan siswa dari pra siklus, siklus I dan siklus II dapat dilihat pada tabel dalam lampiran.

Penelitian tindakan kelas ini dilaksanaan sebagai upaya untuk meningkatkan aktivitas dan Prestasi belajar Bahasa Indonesia pada materi Puisi melalui penerapan Model Pembelajaran Picture and Picture. Dimana penelitian ini dilakukan dalam dua siklus yang didasarkan pada cakupan materi Puisi.

\section{KESIMPULAN}

Berdasarkan hasil penelitian dan pembahasan diatas, dapat di simpulkan bahwa Penerapan Model Pembelajaran Picture and picture dapat meningkatkan aktivitas dan Prestasi belajar siswa pada materi Puisi di SDN 2 Dasan Lekong. Peningkatan tersebut dapat dilihat dari perolehan nilai skor aktivitas siswa, aktivitas guru dan nilai rata-rata kelas serta tingkat ketuntasan secara klasikal pada tiap siklus mengalami peningkatan baik pada siklus I maupun siklus II. Dari hasil penelitian dan pembahasan di atas dapat disimpulkan: (1) Penerapan Model Pembelajaran Picture and Picture dapat meningkatkan Prestasi belajar Bahasa Indonesia Materi Puisi pada siswa Kelas II semester II SDN 2 Dasan Lekong Tahun Pelajaran 2020/2021. (2) Penerapan Model Pembelajaran Picture and Picture dapat meningkatkan aktivitas belajar para siswa pada mata pelajaran Bahasa Indonesia Materi Puisi siswa Kelas II semester II SDN 2 Dasan Lekong Tahun Pelajaran 2020/2021 yang dapat dilihat dari peningkatan aktivitas belajar dari siklus I sampai dengan siklus II, dari kategori Cukup Aktif dengan nilai rata-rata 3,2 sampai dengan kategori Aktif dengan nilai rata-rata 4,1. (3) Prestasi belajar siswa pada mata pelajaran Bahasa Indonesia Kelas II semester II di SDN 2 Dasan Lekong Tahun Pembelajaran 2020/2021 mengalami peningkatan pada setiap siklus dengan persentase ketuntasan secara klasikal masing-masing siklus yaitu siklus I sebesar $70 \%$ dan siklus II sebesar $100 \%$ berarti ada kenaikan $30 \%$.

\section{DAFTAR PUSTAKA}

Anzar, S. F., \& Mardhatillah, M. (2018). Analisis Kesulitan Belajar Siswa Pada Pembelajaran Bahasa Indonesia di Kelas V SD Negeri 20 Meulaboh Kabupaten Aceh Barat Tahun Ajaran 2015/2016. Bina Gogik: Jurnal Ilmiah Pendidikan Guru Sekolah Dasar, 4(1).

Ashlihah, A., Mufidah, R. L., \& Aditiya, Y. N. (2020). Peningkatan Pemahaman Agama terhadap Santri TPQ melalui Media Belajar Picture and Picture. Jumat Keagamaan: Jurnal Pengabdian Masyarakat, 1(1), 38-41.

Daryanti, D., \& Taufina, T. (2020). Penggunaan Media Pembelajaran dalam Model Picture and Picture untuk meningkatkan Hasil Belajar Siswa. Jurnal Basicedu, 4(2), 484-490.

Dewi, N. N. K., Kristiantari, M. R., \& Ganing, N. N. (2019). Pengaruh Model Pembelajaran Picture and Picture Berbantuan Media Visual terhadap Keterampilan Menulis Bahasa Indonesia. Journal of Education Technology, 3(4), 278-285.

Ependi, S. (2018). Penerapan Metode Tanya Jawab Untuk Meningkatkan Prestasi Belajar Bahasa Indonesia siswa Kelas VI SD Negeri 012 Pangkalan Baru Kecamatan Siak Hulu. Primary: Jurnal Pendidikan Guru Sekolah Dasar, 7(2), 256-264.

Farhurohman, O. (2017). Implementasi Pembelajaran Bahasa Indonesia di SD/MI. Primary: Jurnal Keilmuan dan Kependidikan Dasar, 9(1), 23-34.

Prihatiningsih, E., \& Setyanigtyas, E. W. (2018). Pengaruh Penerapan Model Pembelajaran Picture And Picture Dan Model Make A Match Terhadap Hasil Belajar Siswa. JPsd (Jurnal Pendidikan Sekolah Dasar), 4(1), 1-14. 
Putri, I. G. A. C. A., Putra, D. K. N. S., \& Zulaikha, S. (2014). Pengaruh metode pembelajaran SQ3R terhadap hasil belajar bahasa Indonesia kelas V SD. Mimbar PGSD Undiksha, 2(1).

Rahmawati, A., \& Nartani, C. I. (2018). Kompetensi Sosial Guru Dalam Berkomunikasi Secara Efektif Dengan Siswa Melalui Kegiatan Pembelajaran Bahasa Indonesia Di Sd Negeri Rejowinangun 3 Kotagede Yogyakarta. Trihayu, 4(3), 259031.

Raslimin, W. O., \& Anhusadar, L. (2018). PENERAPAN SIKAP TERHADAP PRESTASI BELAJAR BAHASA INDONESIA PADA SISWA MTsN I WAKATOBI. Zawiyah: Jurnal Pemikiran Islam, 4(1), 115-135.

Santo, Z., Kimbay, M. M., \& Werang, B. R. (2018). Pengaruh Dukungan Orang Tua Dan Motivasi Belajar Terhadap Prestasi Belajar Bahasa Indonesia Siswa Sd Yppk Maria Fatimah Merauke. Magistra: Jurnal Keguruan Dan Ilmu Pendidikan, 5(2), 053-063.

Widiyarto, S. (2018). Pengaruh metode cooperative scrift dan peran orang tua terhadap prestasi belajar bahasa indonesia. Khazanah Pendidikan, 11(1). 